International Research Journal of Engineering, IT \& Scientific Research
Available online at https://sloap.org/journals/index.php/irjeis/
Vol. 6 No. 1, January 2020, pages: 11-17
ISSN: 2454-2261
https://doi.org/10.21744/irjeis.v6n1.847

\title{
Alternative Psychological Improvement for Karate-Do Trainers from Santiago de Cuba
}

\author{
Mariano Cesar Gurris Suarez ${ }^{\text {a }}$ \\ Hilda Rosa Rabilero Sabatés ${ }^{\text {b }}$
}

Article history:

Submitted: 18 November 2019

Revised: 09 December 2019

Accepted: 22 January 2020

\section{Keywords:}

alternative of psychological;

karate-do;

overcoming for trainers;

psychological component;

Santiago de Cuba;

\begin{abstract}
The psychological overcoming of trainers in Karate-Do the province of Santiago de Cuba still does not meet the demands of contemporary martialsports practice, which becomes the presence of an epistemological gap in relation to theoretical knowledge-practical and the acquisition of professional skills, showing flaws in their professional performance, constituting this the main problem of research. For this reason, it is proposed as a practical contribution an alternative for professional improvement aimed at the preparation of the psychological component in trainers Karate-Do, aimed at eliminating the inadequacies that are manifested in the practice of this sport. For this, scientific methods of the theoretical, empirical, mathematicalstatistical level and techniques such as interview, survey and psychological tests were used. The theoretical references of the preceding authors constitute valuable contributions whose results enrich the systematic work of martial artists, by attending to the various characteristics of athletes during the training stage and the competitive.
\end{abstract}

International research journal of engineering, IT \& scientific research (C) 2020.

This is an open access article under the CC BY-NC-ND license (https://creativecommons.org/licenses/by-nc-nd/4.0/).

\section{Corresponding author:}

Mariano Cesar Gurris Suarez,

Department of Environmental Consulting, Santiago de Cuba.

Email address: marianocesar.gurris@nauta.cu

a Department of Environmental Consulting, Santiago de Cuba

b University Professors, Venezuela 


\section{Introduction}

A powerful and effective tool for sport trainers Karate-Do of these times must be Psychological Overcoming, with it invaluable results are achieved that in the short, medium and long term we wish to obtain from our young athletes, making them men and women with personal and professional values, worthy paradigms of our contemporary society of the present and future (González Figueredo, 2009). That is why it is necessary to raise the psychological training of these trainers, deepening knowledge and skills that allow them to act with greater autonomy and critical capacity, take into account the needs and characteristics of practitioners, strengthen their strengths, generate well-being and take advantage of the practice of sport as a source of personal development, including values, which constitutes a necessity, since we are in a historical-social moment where sport increasingly acquires a relevant role in the lives of citizens as an instrument of education, health and recreation and where negative influences derived from the professionalization, commercialization and media manipulation of which it is the object are also appreciated.

\section{Materials and Methods}

To comply with the objectives set, an intentional sample of trainers from the Karate-Do team of the province of Santiago de Cuba was worked on. The population in an investigation is understood as the totality of elements that meet the characteristics required to carry out the said investigation. According to Pineda \& De Alvarado (1994), the population is "The set of individuals or objects that you want to know something about in an investigation." For its part, the type of sampling is intended as, according to Tamayo \& Tamayo (2000). "It is in which the researcher selects the elements that in his opinion were representative, which requires the researcher a prior knowledge of the population being investigated to determine which the categories that can be considered representative are.

\section{Methods theoretical level}

Analytical - Synthetic: for the study that is carried out throughout the investigation through the updated bibliography, as well as for the analysis, the interpretation of the results, since it is present in each part and moment of the steps that are rush into this process.

Inductive - deductive: to make the necessary inferences in the application of empirical, theoretical, statistical methods, and arrive at conclusions.

Systemic - structural-functional: it was used in the development of the sociopsychological intervention plan to improve the psychological preparation of trainers Karate-Do, allowing them to establish and determine its components.

\section{Methods of the empirical level}

The scientific observation: allowed to know the current state of the trainers.

Document analysis: the documents analyzed were the training plan for trainers for karate records, calls, and competitions.

\section{Techniques}

Interview: it is applied to the athletes of the teams Karate-Do with the purpose of knowing the characteristics of the teams in terms of psychological preparation since it allows them to have direct information on the aspects related to the present investigation.

The interview with the athletes of the Karate-Do team was carried out in order to know their opinions on:

Participation in the process of setting the training and competition objectives.

\section{Specific objectives}

To elaborate an alternative from the professional overcoming for the preparation of the psychological component of the trainers of Karate-Do the province of Santiago de Cuba and directed to the implementation of actions from the martial-sports practice during the training process. 


\section{Results and Discussions}

\section{Develop an appropriate distribution of roles}

Requirements to consider in the implementation of the plan.

a) Participants sit in a circle, as close as possible to each other. The coach of the team is also included here. This way of proceeding is based on the achievement of favorable atmospheres and on the reduction of the psychological distance between the members, generated before the physical proximity and the visibility of one another during the sessions.

b) Commit emotionally to each subject with participation in the sessions from the awareness of the problems that affect the performance of the team and are necessary to eliminate to achieve the understanding of psychological preparation.

c) Check compliance with the objectives and goals proposed in the previous sessions.

d) Perform the corresponding feedback in each session.

e) Verify the results of the actions.

What is meant by psychological improvement?

The psychological overcoming is called in different ways:

Dosil (2004) is called mental training and consists, according to its definition, in providing athletes with a series of psychological strategies to acquire the ability to cope with training and training. competitions in the best possible way, that is, it is a specific job to increase the performance and well-being of the athlete or anyone in the context of the sport. Gould (2009) calls it mental preparation and defines it as the cognitive, emotional and behavioral strategies used by athletes and teams to achieve an ideal state of execution that is related to optimal psychological states and high performance in competition or practice.

For Rudik, a Russian psychologist and one of the parents of this science, psychological preparation is the development of the set of qualities and psychic properties of the athlete on whom the perfect and reliable performance of sports activity depends on the extreme conditions of training and the competencies (Barrios, 2014; Sainz, 2009).

In the work of transforming the existing reality, the coach can employ a variety of methods and techniques depending on the nature of the problems, characteristics of the athletes and skills for their application:

a) The respectful, sincere and participatory conversation with athletes and family members.

b) The individual or group instructional talk.

c) The modeling or simulation of situations that favor awareness or develop skills in managing contingencies.

d) Feedback and reinforcement of desired behaviors.

e) The approach of attainable goals in the short term.

f) The suggestion of self-instructions or self-mandates.

g) Orientations that favor emotional regulation.

h) Orientations that favor self-esteem and self-confidence.

i) Orientations that favor concentration and mental representation of motor actions.

The conflicts that appear between coaches and athletes are related to the inaccuracies and lack of communication (García Ucha, 1999).

a) Inability to understand athletes

b) Set preferences for one or another athlete

c) Undercover rejection of some or more particular characteristics, the rejection that emerges in situations of great stress or emotional load.

d) Establish generalities, which are based in stereotypes formed previously.

e) Inability to provide emotional support, even if it is not advisable to get involved in them.

f) Issue judgments against athletes guided only by their previous experience, without delving into the possible causes.

g) They underestimate the role of body language using it indiscriminately without worrying about the influence that their gestures, mimics, postures sound, tones of voice can have on athletes.

h) A tendency to be strong to the new, to be inflexible and when it comes to new acquisitions.

Suarez, M. C. G., \& Sabatés, H. R. R. (2020). Alternative psychological improvement for karate-do trainers from Santiago de Cuba. International Research Journal of Engineering, IT \& Scientific Research, 6(1), 11-17. 
What is the role of the sports coach in the preparation of the psychological component?

The coaches (García Ucha, 1999; Singh \& Parmar, 2015), through the performance of their pedagogical work in sport, in our opinion also fulfill the following psychological preparation functions:

a) Promote a psychological climate, which must be positive, inside and outside the training and competition session, capable of stimulating interest in the activity, obtain satisfaction and promote the development of the potential of the athlete.

b) Prepare the athlete to face the different contingencies generated by training and competition, especially when practiced for the purpose of improvement and / or high competition.

c) Contribute to the increase of motivation through your work as a counselor in learning and performance goals, leading athletes towards achieving their aspirations.

d) Influence self-confidence and emotional regulation during the execution of training and competition tasks.

e) Promote values and positive experiences in athletes

The coach establishes close relationships with athletes and can achieve an appreciable capacity for professional and personal influence on them. Aware of the role they play, we derive the need to take advantage of it and strengthen it. The coach must face his responsibility as head of sports preparation, including psychological preparation, consciously, positively and with sufficient knowledge, since attitudes and behaviors that generate psychological climates and unfavorable influences, due among others, are also frequently appreciated. causes improper management of communication or resources to stimulate motivation, emotional regulation or self-confidence.

What principles should the coach take into account in his role as a psychological trainer?

a) The establishment of close coach-athlete communication, based on principles of respect, empathy and sincerity.

b) Consider the athlete as an integral person, in terms of his identity as a person and not only from the perspective of his activity in sports.

c) Take into account their experiences. Conceive that they have needs and experiences that need to be exploited to enhance improvement and performance.

d) Recognize and stimulate all behavior that goes in the direction of persistence, confronting difficulties and improving indices linked not only to physical or technical-tactical aptitude, but also to self-confidence, emotional regulation, and enjoyment of the activity or others that constitute an expression of human growth.

e) Do not prosecute. If certain behaviors need modification, invite reflection, do it with respect, in the appropriate manner, time and place, mobilizing their active participation in the process of behavioral modification.

f) An inviolable principle is the confidentiality of personal information obtained through communication with the athlete, family or the use of questionnaires, interviews or other instruments. The establishment of close coach-athlete communication, based on principles of respect, empathy and sincerity.

What psychological skills should the coach develop in his athletes?

You may need the development of numerous skills, given among other factors by the type of sport, the stage of development you are in, the stage of preparation and the characteristics of athletes.

In general, the following could be considered as essential:

a) Being able to set short, medium and long term objectives.

b) Maintain positive mental attitudes before each stage of development or difficulty in the preparation process.

c) Knowing how to regulate oneself in training and in competition.

d) Maintain self-confidence at all times.

e) Find solutions for each task that arises.

f) Know how to consider self-affirmations, self-instructions, and self-reinforcements.

g) Know how to stay focused and how to recover it.

h) Mentally represent your actions, goals, emotions

The coach must be perceived as an effective model and example (Sainz, 2009). You cannot fall into inconsistent behaviors between what you ask of the athletes and their own behavior, if this happens, you will lose prestige before your athletes, and you will not have the moral strength to demand them (Jiménez Sánchez, 2012). 


\section{Coach Functions}

a) Teacher: communicating new knowledge, skills, and ideas.

b) Coach: improving the physical condition of athletes.

c) Instructor: directing athletes and their exercise.

d) Motivator: creating decisive and positive proposals.

e) Disciplined: determining the system of rewards and punishments.

f) Director: organizing and planning.

g) Administrator: engaging in administrative matters.

h) Social worker: advising.

i) Friend: giving support.

j) Scientist: analyzing, evaluating and solving problems.

k) Student: willing to listen, learn and accumulate new knowledge. (Thompson, 1991).

To contribute to the psychological improvement of the coach in our country, the psychologist participates in:

a) Teaching postgraduate courses on Sports Psychology.

b) Participation in methodological preparation activities.

c) Joint preparation of training plans.

d) Psychological control of sports training.

e) Periodic checks of the athlete's preparation.

f) Support and psychological help to the coach.

What psychological methods can trainers use?

Sports Psychology is characterized by a methodological pluralism (Wylleman \& Lavallee, 2004; Dopico, 2012), that includes a wide range of resources to evaluate, interpret and modify human behavior. There may be cited systematic observation, experimental methods (laboratory, natural or field), non-experimental methods (archival research, case studies, interviews, surveys, tests, and analysis of activity results) and statistical methods. In the work of transforming the existing reality, the coach can employ a variety of methods and techniques depending on the nature of the problems, characteristics of the athletes and skills for their application:

a) The respectful, sincere and participatory conversation with athletes and family members.

b) The individual or group instructional talk.

c) The modeling or simulation of situations that favor awareness or develop skills in managing contingencies.

d) Feedback and reinforcement of desired behaviors.

e) The approach of attainable goals in the short term.

f) The suggestion of self-instructions or self-mandates.

g) Orientations that favor emotional regulation.

h) Orientations that favor self-esteem and self-confidence.

i) Orientations that favor concentration and mental representation of motor actions.

What are the basic conditions for the performance of the psychological preparation work by the coach?

Three basic conditions are required to perform the psychological preparation work:

a) Technical and organizational knowledge of the sport.

b) Knowledge of the psychological demands of the sport.

c) Knowledge of the characteristics and psychological factors that influence the athlete's behavior.

In the first two conditions, the coach has the knowledge or can access them. In the third condition, it is necessary not only to observe but also to deepen with the help of diagnostic instruments, which requires the participation of a psychology professional (González Maura, 1995; Rubinstein, 1969; Iriani, 2018). But the coach needs and can access a minimum of information pertaining to the third condition given his permanent relationship with the athlete and knowledge of the performance that he is achieving. For this, it must develop the capacity of observation and analysis. It is essential to know: the objectives pursued by the athlete; the sociodemographic characteristics (age, cultural level, socioeconomic level, characteristics of the family environment); outstanding aspects of its academic, personal, family and sports history.

Suarez, M. C. G., \& Sabatés, H. R. R. (2020). Alternative psychological improvement for karate-do trainers from Santiago de Cuba. International Research Journal of Engineering, IT \& Scientific Research, 6(1), 11-17. 
In this way, we agree with Michael B. Frisch in defining that Quality of Life is the degree to which the most important needs, goals and desires have been fulfilled. General satisfaction status, derived from the realization of the potential of the person. In conclusion, we ask ourselves the following question: What objectives should be proposed as a training or improvement program for physical culture professionals in relation to their psychological dimension? The answer is synthesized in four directions:

a) Deepen knowledge and basic psychological skills for communication management, motivation, emotional regulation, self-confidence, reinforcement and behavioral modification, education of volitional qualities and dynamics management group, which are very important in the work of psychological preparation.

b) Deepen the psychological problems that most frequently occur in the practice of physical activities, their causes and possible ways of confrontation.

c) Contribute to the development of a professional capable of critically assessing and exploiting the currents of thoughts and psychological contributions that exist worldwide and in Latin America, according to the needs and characteristics of the social context and the activity in which it operates.

d) Encourage research interest towards psychological problems in the university context of the training of specialists in Physical Culture and Sports.

\section{Conclusion}

This work seeks to deepen the function of psychological improvement performed by the coach. It has been found that there are inadequacies in the knowledge and development of skills to effectively confront the psychological problems arising from the activity itself or from the characteristics of the athletes. In addition, the need to define a position in this regard has been determined and it has been suggested that the most important thing is the attention to the human being. Finding effective answers to the problem of the coach's role as a psychological trainer travels through the cultivation of a critical attitude and search not only theoretical but also empirical in the daily work of the Physical Culture professional.

\section{Conflict of interest statement}

The authors declared that they have no competing interests.

\section{Statement of authorship}

The authors have a responsibility for the conception and design of the study. The authors have approved the final article.

\section{Acknowledgments}

We thank the group of the teacher of the master's degree and the study partners, who helped the development of the research. 


\section{References}

Barrios, R. (2014) Psychological intervention in sport. Handwritten conference for basic training course for psychologists in sport at IMD. Havana.

Dopico, H. (2012). Sports Psychology: branch of Sports Psychology or Science? EFDeportes.com, Digital Magazine. Buenos Aires, No. 168. http://www.efdeportes.com/efd168/psicologia-del-deporte-rama-o-ciencia.htm

Dosil, J. (2004). Psychology of physical activity and sport. Madrid: McGraw-Hill.

García Ucha, F. (1999). Coaches and burnout. http://www.efdeportes.com/efd28/burnout1.htm

García Ucha, F. (1999). The sports coach http://www.efdeportes.com/efd14/gucha.htm

González Figueredo. M. (2009). The psychological preparation in sport. Digital Magazine - Buenos Aires No. 133. June 2009.

González Maura, V. (1995). Psychology for educators. Havana city. Editorial People and Education.

Gould, D. B. (2009). Moving politics: Emotion and ACT UP's fight against AIDS. University of Chicago Press.

Iriani, D. H., Syahdan, -, \& Nuriadi, -. (2018). The effect of early English learning on psychology. International Journal of Social Sciences and Humanities, 2(1), 65-74. https://doi.org/10.29332/ijssh.v2n1.82

Jiménez Sánchez, Y (2012). The role of the coach in the application of sports training psychology. Digital magazine. Year 15. No. 166. Buenos Aires. May 2012.

Pineda, A., De Alvarado, E. L., \& Francisca, H. (1994). de Canales. Metodología de la investigación. Unidad VI, 5.

Rubinstein JL. (1969). Principles of General Psychology. Havana. Revolutionary Edition

Sainz, N. (2009). Psychology of Physical Education. Havana Cuba.

Sainz, N. (2009). Topics for coaches. Havana Cuba.

Singh, A., \& Parmar, D. S. (2015). A comparative study of competitive anxiety between basketball and volleyball players. International Research Journal of Management, IT and Social Sciences, 2(1), 1-4.

Tamayo, Y. \& Tamayo, M. (2000). Técnicas de Investigación Social. Bogotá, Colombia. Editorial Limusa.

Thompson, P. J. (Ed.). (1991). Introduction to coaching theory. International Amateur Athletic Federation.

Wylleman, P., \& Lavallee, D. (2004). A developmental perspective on transitions faced by athletes. Developmental sport and exercise psychology: A lifespan perspective, 507-527.

\section{Biography of Authors}

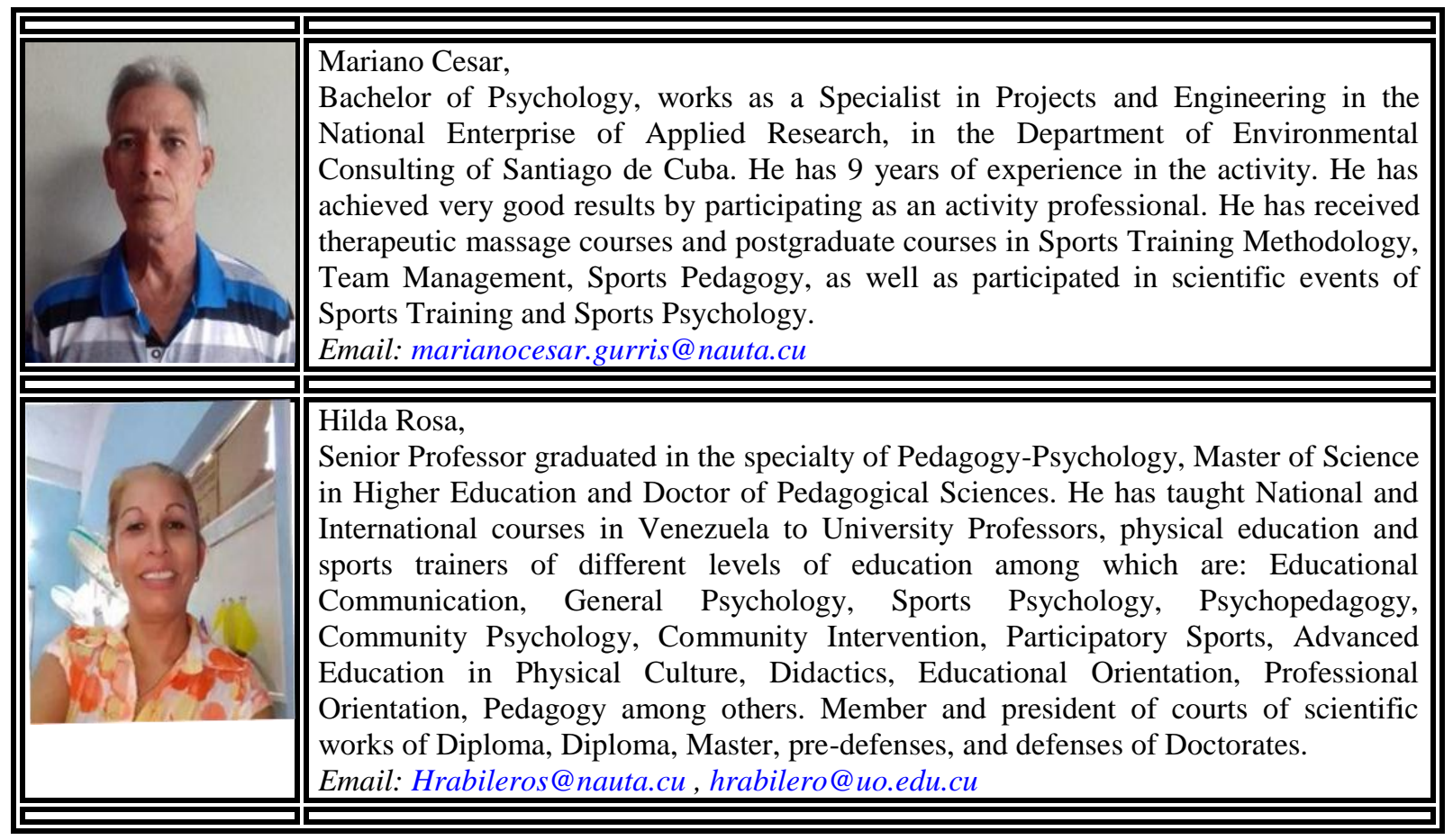

Suarez, M. C. G., \& Sabatés, H. R. R. (2020). Alternative psychological improvement for karate-do trainers from Santiago de Cuba. International Research Journal of Engineering, IT \& Scientific Research, 6(1), 11-17.

https://doi.org/10.21744/irjeis.v6n1.847 